\title{
DIREITO À MEMÓRIA E MUSEUS
}

\author{
Andréa Fernandes Considera'
}

Universidade de Brasília

\section{RESUMO:}

Este artigo pretende discutir as relações entre o direito à memória e as práticas museais que vem sendo desenvolvidas em museus voltados para preservação destas memórias. Neste debate surgem questões que tentam identificar as possibilidades e limitações da instituição museu enquanto "depositário" de memórias e reprodutor de relações de poder.

\section{PALAVRAS CHAVE:}

Museu; Direito à Memória; Poder

\section{The Right to Memory and Museum}

\section{ABSTRACT:}

This article aims to discuss the relationship between the right to the memory and museum practices that have been developed in museums aimed at preserving these memories. Questions arise in this debate that attempt to identify the possibilities and limitations of the museum institution as "keeper" of memories and reproducer of relations of power.

\section{KEYWORDS:}

Museum, The Right to Memory, Power 


\section{Sobre Museus}

As instituições que conhecemos hoje - disseminadas por boa parte do mundo - sob a denominação de Museus, surgiram no século XVIII a partir de uma dupla vontade: por um lado, a de preservar objetos e coleções representativos de alguma memória; por outro lado, de comunicar e tornar pública esta memória, o que por sua vez garantiria o discurso desejado, dando, inclusive, notoriedade ao seu autor.

Neste movimento, tanto as grandes obras de arte encomendadas à pintores famosos com o intuito de consagrar acontecimentos históricos, quanto novas espécies de animais taxidermizados com seus nomes científicos coletados nos mais distantes e exóticos lugares do planeta, serviam como suporte de uma memória a ser perpetuada para, desta forma, construírem referenciais os mais próximos possíveis de uma desejada verdade.

Os museus, no entanto, sempre foram instituições em constantes transformações que para sobreviverem ao tempo, precisam se recriar constantemente sem abrir mão de seus fundamentos: os objetos (e coleções) e a comunicação destes. E é essa capacidade de sobrevivência e criação de narrativas persuasivas e discursos contemporâneos que colocam os museus muitas vezes no centro de grandes disputas de poder; o poder de guardar objetos representativos da memória.

Entendendo os Museus como lugares de memória e de poder, torna-se pertinente questionar a forma como os museus têm atuado junto à sociedade e como suas ações têm garantido ou negligenciado o direito à memória.

Neste sentido, não tratarei aqui de um museu em especifico, mas sim da instituição museal como lugar de memória, criado por e para as sociedades que deles se utilizam.

A questão torna-se mais complexa na medida em que os museus são não só lugares de memória, mas também lugares de poder; de disputa pelo poder através da memória. Não é por acaso que na mitologia grega, as musas são filhas de Mnemosine e Zeus, ou seja, da memória com o poder.

Com relação ao direito à memória, os museus atuam em duas direções. Primeiro, a iniciativa de se eleger um tema e reunir um acervo "representativo" de uma memória a ser preservada, garante a um grupo o direito a ela. Mas por outro lado, o próprio processo de escolha resulta em exclusão de outras memórias, contidas nos objetos não selecionados (não "representativos”).

A segunda direção está na ponta do processo de musealização, que é a exposição dos objetos (geralmente em número menor do que o todo da coleção de um museu, selecionados dentre todos os objetos considerados representativos, para compor a memória a ser transmitida pelo museu) com suas interpretações, histórias e discursos, que mais uma vez legitimam memórias escolhidas.

A estes fatores devemos ainda acrescentar as características da sociedade atual que em geral utiliza a instituição museal como local de visitação estudantil - numa tentativa de diversificar as formas de aprendizado - ou como local turístico. No primeiro caso, temos um nítido exercício de perpetuação da memória às futuras gerações a partir das narrativas construídas pelos mais velhos, pelos 
seus antepassados. Já no último caso, é comum as pessoas conhecerem os museus dos locais turísticos visitados, mas desconhecerem totalmente os museus de sua própria cidade (ou apenas tê-los freqüentado no período escolar como atividade obrigatória). O turista, por sua vez, recebe a narrativa dos museus como informações curiosas, com pouca margem para refletir sobre os contextos e interesses envolvidos na construção das narrativas a eles apresentadas. Mesmo assim, termina por levar consigo uma percepção daquela memória que Ihe foi oferecida.

Desde a década de 1970, em todo o mundo vêm surgindo e se consolidando experiências sociais de museus, preocupados exatamente com o direito à memória, principalmente dos grupos sociais ditos minoritários. Neste sentido surgiram os ecomuseus ${ }^{2}$, os museus comunitários, a sociomuseologia e diversas outras formas de concepção do campo museal. Mas a falta de comunicação, de trocas de conhecimento entre estas instituições e a comunidade em geral, ainda é um problema. Muitos museus comunitários chegam a se constituir como bandeira de luta por direitos humanos básicos, mas seu campo de atuação fica limitado a um grupo social especifico, muitas vezes desconhecido pela própria comunidade maior na qual está inserido3; ou mesmo passam a ser rechaçados por esta 4 .

Num movimento paralelo, surgiram na década de 1990 no Brasil, os museus institucionais e entre eles, os empresariais, também representativos de minorias, contando histórias e guardando memórias de sucessos institucionais e empresariais, por vezes associadas a epopeias familiares, mas que igualmente preservavam memórias de contextos históricos e sociais.

Há, no entanto uma distância entre criar um museu e vivenciá-lo. $O$ direito à memória se manifesta na constituição do museu, na formação do acervo e sua comunicação ao público através das exposições, mas em raros casos o vemos atuante na participação da comunidade. Em outras palavras, os museus são vistos como depositários da memória, para que um dia, quando a lembrança do passado se fizer necessária, os objetos representantes deste passado possam ajudar a despertar a memória. Assim, o Museu do Índio tem sua visitação aumentada no mês de abril; a sala da alegoria do Grito da Independência no Museu Paulista fica lotada apenas próximo ao dia sete de setembro; o Memorial Juscelino Kubitschek comemora nascimento e morte do ex-presidente. Igualmente, a mídia só recorre a eles nestas efemérides, sempre elogiando suas coleções e, em geral, lastimando o seu estado de abandono e o pouco investimento de recursos na preservação da memória. São estas as escolhas e o retrato de como lidamos com as nossas memórias.

2 Tipologia museal mencionada pela primeira vez na década de 1970 por Georges-Henri Rivière e desenvolvida por Hugues de Varine.

3 Um exemplo é o Museu da Maré, um museu comunitário, bandeira de lutas da Comunidade da Favela da Maré, que apesar de desenvolver um trabalho social de imensa relevância, ainda tem uma visitação predominante de membros da própria comunidade ou de turistas, em pacotes que incluem as visitas às comunidades do Rio de Janeiro.

4 Como no caso do Museu Maguta, organizado por índios Ticuna no município de Benjamin Constant (Estado do Amazonas) com o objetivo de preservar a memória de suas tradições para as gerações seguintes e que teve enorme rejeição por parte da comunidade urbana, que não desejava associar a imagem da cidade à existência indígena na região. (Cf. FREIRE, 2009: 217-222) 
Enfim, a grande questão colocada é entender este hiato entre o direito à memória que os museus oferecem e a apropriação que os indivíduos e coletividades fazem deste poder que o museu, enquanto instituição, tem de proporcionar neste acesso à memória/história, em sua recolha, preservação e extroversão.

Neste sentido, este trabalho buscará compreender, a partir de alguns teóricos, os problemas e oportunidades existentes nos museus com relação à preservação de memórias de indivíduos e coletividades.

Museu, História e Direito à Memória

Sima Weingarten (2005), referindo-se ao Museo del Holocausto na Argentina, coloca algumas questões bem próximas das funções que esperamos de um museu comprometido com a preservação da memória:

Las prácticas museísticas, comprometidas en transmitir la Shoá son formas privilegiadas de poner en acto la memoria, facilitando su transmisión. [...] Recordemos que esta tarea de rescatar la memoria pone en acto el mayor compromiso moral por los derechos humanos, la libertad, el pluralismo cultural, la igualdad de las minorías y los valores democráticos.[...] Recordar es asegurar la información y obligar a inscribir los hechos acontecidos en el marco histórico de esa época y a la vez, de nuestro tiempo actual. [...] El deber de memoria se nos impone como un mandato ético irrenunciable, dado que no sólo es una obligación que nos liga a las víctimas del pueblo judío, sino que fortalece la conciencia política e ideológica destinada a evitar reiteraciones nefasta. (Weingarten, 2005: 9-10)

Nestes fragmentos, algumas questões importantes são levantadas. A primeira refere-se ao museu como uma instituição privilegiada para a guarda e disseminação da memória; a segunda dá ao museu o compromisso ético e moral de recuperar a memória dos fatos em nome de questões maiores, como os direitos humanos; a terceira questão colocada é a capacidade dos museus de transformar a memória em história (em que pese a autora recusar a distinção entre memória e história ${ }^{5}$ ), ou seja, prolongar uma memória que se perderia ao final de uma geração, eternizando sua lembrança para as futuras gerações; por fim, a quarta questão ressalta a capacidade dos museus de influenciar a consciência política e ideológica de uma coletividade, orientando o futuro da mesma.

Tais questões, se por um lado demonstram o poder dos museus, também alertam para a enorme responsabilidade de todas as ações museais, cujas consequências refletem diretamente na transmissão das memórias através da história. Neste sentido, os museus são instituições políticas e de poder que constroem narrativas partidárias, muitas vezes camufladas por objetos falsamente legitimadores de memórias.

Avançando na discussão, abordaremos as percepções de Maurice Halbwachs (1990) sobre a memória e a história, mais exatamente do que ele define como uma memória autobiográfica (aquela que nos lembramos de nossas vivências, desde a infância) e uma memória histórica (aquilo que aprendemos sobre um contexto mais amplo de nosso passado e assim associamos às nossas vivências).

5 Conforme o texto do próprio autor, não existe distinção entre história e o dever de memória:"Además, creemos que resulta falsa la oposición entre la historia -entendida como la práctica teórica de un saber riguroso-y el deber de memoria, al que se la confina al lugar de una práctica menor." (Weigarten, 2005: 10) 
Um homem, para evocar seu próprio passado, tem freqüentemente necessidade de fazer apelo às lembranças dos outros. [...] Diríamos mais exatamente ainda: memória autobiográfica e memória histórica. A primeira se apoiaria na segunda, pois toda história de nossa vida faz parte da história geral. [...]. Um acontecimento não toma lugar na série dos fatos históricos senão algum tempo depois que se produziu. É então mais tarde que podemos relacionar aos acontecimentos nacionais as diversas fases de nossa vida. [...] Não é na história aprendida, é na história vivida que se apóia nossa memória. (Halbwachs, 1990: 54-60)

Haveria então duas esferas distintas de memória: aquela que é individual, produzida a partir das lembranças desde a infância e a memória coletiva ou histórica, que é aquela relacionada aos acontecimentos sociais dentro dos quais, inevitavelmente ocorrem os fatos individuais, mas que nem sempre são a eles nitidamente associados, senão no futuro, na construção histórica dos acontecimentos passados.

Neste ponto, cabe trazer à discussão uma das questões mais caras à museologia atual que é a noção de pertencimento. Uma boa exposição museal é aquela que permite ao visitante se identificar com o objeto observado, possibilitando que a partir dele aflorem conhecimentos e memórias. Só assim fará sentido a preservação de um objeto como suporte capaz de evocar lembranças individuais que se associam e se encontram em memórias coletivas. Mas observa Halbwachs:

Ora, se fixamos nossa atenção sobre os grupos maiores, por exemplo a nação, ainda que nossa vida e a de nossos pais ou de nossos amigos estejam compreendidas nela, não podemos dizer que a nação como tal se interesse pelos destinos individuais de cada um de seus membros. [...] A nação está longe demais do indivíduo para que este considere a história de seu país de outro modo do que como um quadro muito amplo, com o qual sua história pessoal não tem senão muito poucos pontos de contato. [...] Mas, entre o indivíduo e a nação, há muitos outros grupos, mais restritos do que esse que, também eles, tem sua memória, e cujas transformações atuam muito mais diretamente sobre a vida e o pensamento de seus membros. (Halbwachs, 1990: 78-79)

Neste contexto vemos hoje, principalmente no Brasil, as iniciativas museológicas muito mais voltadas para a criação de museu comunitários (incentivados inclusive pelo próprio IBRAM/Ministério da Cultura através dos Pontos de Memória) do que para a implantação de novos museus nacionais, destinados a sintetizar contextos históricos mais abrangentes. Os museus comunitários por sua vez, estão mais ligados às memórias de pequenos grupos e, portanto, voltados para temáticas muito mais específicas, relacionados a memórias, ainda que não individuais, mas de pequenas coletividades.

Estes museus, geralmente organizados a partir de relatos orais, surgem de experiências vivas, de memórias ativas e parecem pouco se importar com a existência de uma história nacional, ou se apropriam de seus fatos na medida e na leitura que lhes interessa para a construção de uma história/memória coerente e útil para a vivência de sua comunidade.

Por outro lado, os Museus Nacionais continuam existindo e atualizando sua linguagem. Um exemplo interessante é o recurso museográfico utilizado 
atualmente no Museu Histórico Nacional. Começando pela história do Brasil a partir das lendas indígenas, atravessamos uma seqüência de salas cronologicamente organizadas que nos guiam com textos, imagens e objetos através dos séculos de história, até chegarmos próximo dos dias atuais.

Como nenhum de nós viu os navios de Cabral aportar aqui, nem assistiu à assinatura da Lei Áurea, tais fatos precisam ser narrados em textos, imagens e objetos, pois não fazem parte da memória individual dos visitantes. Mas há uma última sala do museu, onde não há nenhuma palavra, nenhuma imagem explicativa; apenas inúmeros objetos do cotidiano brasileiro dos últimos 80 anos, incluindo utensílios domésticos, brinquedos (do carrinho de rolimã à boneca Barbie), objetos de higiene pessoal (do pó-de-arroz ao creme dental Kolynos).

Os visitantes, que atravessam todo aquele labirinto de salas em total silêncio - em parte porque estão reverenciando um local quase sagrado onde estão eternizados personagens de nossa história, em parte porque não têm informações para acrescentar ou discordar, porque não vivenciaram aqueles fatos - na última sala, passam a narrar aliviados uma infinidade de histórias associadas aos objetos que trazem a memória de seu próprio passado ou de seus antepassados próximos (- na casa do meu avô tinha este objeto!). Independente da idade, o visitante se sente confortado em reconhecer ali a sua história e compreender que esta sua história é o momento presente de todo um passado não vivido, mas aprendido nas salas anteriores do museu. Segundo Halbwachs,

Se conclui que a memória coletiva não se confunde com a história. [...] A história, sem dúvida, é a compilação dos fatos que ocuparam o maior espaço na memória dos homens. Mas lidos em livros, ensinados e aprendidos nas escolas, os acontecimentos passados são escolhidos, aproximados e classificados conforme as necessidades ou regras que não se impunham aos círculos de homens que deles guardaram por muito tempo a lembrança viva. Enquanto uma lembrança subsiste, é inútil fixála por escrito, nem mesmo fixá-la, pura e simplesmente. [...] Quando a memória de uma sequência de acontecimentos não tem mais por suporte um grupo (...) então o único meio de salvar tais lembranças, é fixá-las por escrito em uma narrativa seguida uma vez que as palavras e os pensamentos morrem, mas os escritos permanecem. [...] Certamente, um dos objetivos da história pode ser, exatamente, lançar uma ponte entre - passado e o presente, e restabelecer essa continuidade interrompida. (Halbwachs, 1990: 80-8I)

Passemos então a falar do objeto em si, exposto no museu. Para isso é importante recuperar a análise que Paul Ricoeur faz do conceito platônico da eikon, ou seja, a representação presente de uma coisa ausente. No museu, o objeto presente não se reduz a sua matéria; ao contrário, ele está ali representando um fato, um conceito histórico, ou mesmo uma emoção. Um objeto de tortura em ferro do período da escravidão se expõe para representar um fato ausente, seja ele o castigo corporal comumente submetido aos escravos, seja o processo arcaico de fundição do ferro no período colonial, ou mesmo a dor produzida por aquele objeto.

Mas para que o objeto evoque o fato ausente, é preciso, segundo Ricoeur, a mediação da imaginação ou da memória. 
O problema suscitado pela confusão entre memória e imaginação é tão antigo quanto a filosofia ocidental. Sobre esse tema, a filosofia socrática nos legou dois topois rivais e complementares, um platônico, o outro aristotélico. $O$ primeiro, centrado no tema de eikon, fala de representação presente de uma coisa ausente; ele advoga implicitamente o envolvimento da problemática da memória pela da imaginação. O segundo, centrado no tema da representação de uma coisa anteriormente percebida, adquirida ou aprendida, preconiza a inclusão da problemática da imagem na da lembrança. É com essas versões da aporia da imaginação e da memória que nos confrontamos sem cessar. [...] o recurso à categoria de similitude para resolver o enigma da presença do ausente, enigma comum à imaginação e à memória. (Ricoeur, 2007:27-28)

Retornando ao objeto mencionado, é possível imaginar a dificuldade de sua fabricação, a dor provocada pelo seu uso, mas tudo isso se limita ao campo da imaginação (dotada, sem dúvida, de uma enorme capacidade criativa). Mas para aquelas pessoas que experimentaram no passado o seu uso, há a memória "gravada no bloco de cera" de modo que aquele objeto não representa possibilidades de compreensão de um passado, mas sim o próprio passado, o acontecido.

Poderíamos dizer que no campo da imaginação, o objeto no museu representa o coletivo, segue um modelo, um padrão de acontecimentos semelhantes, toma de todos os fatos individuais aquilo que é repetitivo e o ressalta; no campo da memória, o objeto do museu é único para cada indivíduo que dele se apropria de acordo com suas lembranças, carregadas de emoções inacessíveis ao visitante que não experimentou em sua vivência o contato com aquele objeto que está no museu.

Entendemos então que o objeto no museu serve como apoio à imaginação e à memória, mas quando tratamos de objetos muito anteriores às nossas experiências pessoais, a forma como o objeto é exposto poderia induzir a imaginação ao erro, criando uma memória distorcida? Sobre esta questão, Ricoeur faz uma colocação inquietante:

Há mimética verídica ou mentirosa porque há, entre a eikon e a impressão, uma dialética de acomodação, de harmonização, de ajustamento que pode ser bem sucedida ou fracassar. (Ricoeur, 2007: 32)

Ou seja, imaginação e memória em certa medida se ajustam para a construção de uma nova "possibilidade de verdade" no tempo presente, permitindo que o objeto do museu adquirira significados sociais e desperte memórias individuais ou coletivas distintas das que justificou a preservação destes mesmos objetos.

Enquanto passada, a coisa lembrada seria uma pura Phantasie, mas, enquanto dada de novo, ela impõe a lembrança como uma modificação sui generis aplicada à percepção. (Ricoeur, 2007: 65)

Seria então o museu, capaz de sugerir ao presente representações distorcidas de um passado, sem que tal metamorfose fossem percebidas pela lembrança? Segundo Walter Benjamin (1994),

Articular historicamente o passado não significa conhecê-lo 'como ele de fato foi'. Significa apropriar-se de uma reminiscência tal como ela relampeja 
no momento de um perigo. [...] $\bigcirc$ perigo ameaça tanta a existência da tradição como os que a recebem. (Benjamim, 1994: 224)

E mais adiante, Benjamin acrescenta:

Nunca houve um monumento da cultura que não fosse também um monumento da barbárie. E, assim como a cultura não é isenta de barbárie, não o é, tampouco, o processo de transmissão da cultura. (Benjamim, 1994: 225)

O que Ricoeur indica de forma sutil, Benjamin retrata com sua percepção mais fria da crueldade da humanidade. Independente do museu que se evoque, ele será um "monumento de barbárie", que na tentativa de unir dos mundos - o passado e o presente - recorre a mecanismos (pesquisas, discursos e museografias) que inevitavelmente distorcem a memória e proporcionam ao visitante uma falsa noção de memória do passado, ou em outras palavras, de um passado duvidoso (e este processo pode se dar de modo inconsciente ou proposital).

Se estes autores se preocupam com a transmissão legítima da memória e seus processos de manipulação, Jacques Le Goff (2003) nos proporciona uma compreensão mais amena, entendendo que neste processo de transmissão da memória, é inevitável a reconstrução das "verdades". Citando Pierre Janet, Le Goff observa que a própria história é feita pela linguagem, seja ela oral ou escrita, e, portanto, a memória ao ser transmitida pela linguagem, já incorpora as mudanças e adaptações inerentes a cada tempo histórico.

Assim, Pierre Janet 'considera que $\circ$ ato mnemônico fundamental é $\circ$ comportamento narrativo, que se caracteriza antes de mais nada pela sua função social, pois se trata de comunicação a outrem de uma informação, na ausência do acontecimento ou do objeto que constitui o seu motivo' (...). Aqui intervém a 'linguagem, ela própria produto da sociedade'. (Le Goff, 2003: 42I)

O autor observa ainda a transmissão da memória em povos sem escrita, muitos dos quais apresentam diversas versões bem distintas para um mesmo fato e conclui:

Assim, enquanto a reprodução mnemônica palavra por palavra estaria ligada à escrita, as sociedades sem escrita (...) atribuem à memória mais liberdade e mais possibilidades criativas. (Le Goff, 2003: 426)

Em seguida, o mesmo autor analisa a constituição de diversos museus a partir de 1750 e observa que em diferentes países, alguns elementos da cultura local foram escolhidos como representativos da memória. Segundo ele, em países como a Rússia, a Itália e a Espanha, foram priorizadas as grandes coleções artísticas que se estabeleceram em edifícios grandiosos; já na França, foram as vitórias francesas, o período medieval e a pré-história que melhor representaram a nação; nos países escandinavos foram os museus folclóricos que acolheram a memória popular.

Neste sentido, Le Goff traz ao debate outro tema caro à museologia: os museus enquanto instituições pertencentes ao presente e que tem por função conservar e transmitir uma memória que faça sentido e tenha importância para o momento presente, e não para o passado. Desta forma, será sempre o resultado de uma memória escolhida, selecionada entre tantas outras. Um museu não 
guarda os objetos que se perderam com o tempo, mas aqueles que por algum motivo, sobreviveram ao tempo e fazem parte agora, do presente. Tal mecanismo pode se dar de forma natural ou induzida intencionalmente, para o bem ou para o mal.

A memória é um elemento essencial do que se costuma chamar identidade, individual ou coletiva, cuja busca é uma das atividades fundamentais dos indivíduos e das sociedades de hoje, na febre e na angústia.

Mas a memória coletiva é não somente uma conquista, é também um instrumento e um objeto de poder. São as sociedades cuja memória social é, sobretudo, oral, (...) aquelas que melhor permitem compreender esta luta pela dominação da recordação e da tradição, esta manifestação da memória. (Le Goff, 2003: 469-470)

Deste ponto avançamos então para a questão do museu como lugar de memória e de história. Pierre Nora (1993) estabelece uma distinção entre memória e história que deixa claro o limite de ambas:

Memória, história: longe de serem sinônimos, tomamos consciência que tudo opõe uma à outra.A memória é a vida, sempre carregada por grupos vivos (...). A história é a reconstrução sempre problemática e incompleta do que não existe mais. A memória é um fenômeno sempre atual, um elo vivido no eterno presente; a história, uma representação do passado.

(Nora, 1993: 9)

Desta forma, seriam os museus portadores de histórias e não de memórias no sentido que conhecemos? Onde estaria então o direito à memória que os museus logram oferecer?

Se ninguém sabe do que o passado é feito, uma inquieta incerteza transforma tudo em vestígio, indício possível, suspeita de história com a qual contaminamos a inocência das coisas. Nossa percepção do passado é a apropriação veemente daquilo que sabemos não mais nos pertencer. (Nora, 1993: 20)

Mas uma colocação de Pierre Nora procura responder diversos pontos com os quais a museologia vem se debatendo nas últimas décadas.

O que os constitui é um jogo da memória e da história. (...) Inicialmente, é preciso ter vontade de memória. (...) $\mathrm{Na}$ falta dessa intenção de memória os lugares de memória serão lugares de história. (...) Porque, se é verdade que a razão fundamental de ser de um lugar de memória é parar o tempo, é bloquear o trabalho do esquecimento, fixar um estado de coisas, imortalizar a morte, materializar o imaterial para (...) prender o máximo de sentido num mínimo de sinais, é claro, e é isso que os torna apaixonantes: que os lugares de memória só vivem de sua aptidão para a metamorfose, no incessante ressaltar de seus significados. (Nora, 1993:22)

Os museus representativos de pequenas comunidades ou grupos sociais, surgem a partir da "vontade de memória", e por isso apresentam algumas características peculiares: o espaço do museu passa a ser re-significado e torna-se um espaço múltiplo de participação popular, envolvendo atividades sociais e recreativas, tão caras àquele grupo, quanto a sua própria memória. São instituições dinâmicas, com seus conflitos de poder e de "incessante metamorfose", garan- 
tindo o direito à memória. Uma memória atualizável, passada entre gerações na medida dos seus interesses. Nos museus comunitários principalmente, o direito à memória é também o direito à liberdade de expressão; de construção de memórias que lhes são convenientes a cada momento.

Para Pierre Nora, os museus também são lugares de memória, cuja função é parar o tempo e impedir o esquecimento. Mas o tempo e a memória não estão no objeto preservado pelo museu e repleto de significados trazidos pela memória do passado; ao contrário, tempo e memória fazem parte do homem do presente e da leitura que ele faz hoje, dos objetos e narrativas que outrora seus antepassados decidiram perpetuar enquanto memória.

Refletir sobre o papel dos museus nos dias de hoje, principalmente quando entramos na seara dos direitos humanos, mas especificamente no direito à memória, não é tarefa das mais simples. Como pode ser visto nos textos dos autores citados (e poderíamos ter escolhido uma infinidade de outros autores que tratam do tema), o direito à memória é também direito ao esquecimento $\mathrm{e}$ à lembrança daquilo que se quer transmitir às futuras gerações.

Portanto, não há neutralidade em nenhuma iniciativa de preservação de memórias, seja ela no campo dos próprios processos museais, seja no campo da pesquisa histórica. $\bigcirc$ que temos são "versões sobre um mesmo tema", tão duvidosos e aparentemente verdadeiros quanto seus pares. Mas a instituição Museu vem desde a antiguidade mais remota demonstrando ser um elemento social do tempo presente e por isso em constante metamorfose.

Chegamos a não encontrar paralelos entre o templo das musas, o Louvre e o Museu da Maré (apesar de todos serem considerados museus), mas reconhecemos em cada um deles iniciativas sinceras de homens que, em seu tempo, se preocuparam com a memória; mas do que isso, com o direito à memória e se expressaram através desta instituição tão conceitualmente volátil e abrangente que é o Museu.

Enfim, após as reflexões acima apresentadas, podemos concluir que os museus são espaços complexos de poder, privilegiados para ações de preservação de memórias escolhidas dentro de dinâmicas sociais as mais diversas. Neste sentido, se por um lado o museu pode ser usado como instrumento garantidor do direito à memória, por outro lado, faceta da mesma ação, proporciona também o esquecimento, violando o mesmo preceito do direito à memória.

\section{Bibliografia}

BENJAMIN,Walter. Magia e técnica, arte e política: ensaios sobre literatura história da cultura. $7^{a}$ edição. São Paulo: Brasiliense, 1994.

FREIRE, José Ribamar Bessa. A descoberta do museu pelos índios. In: ABREU, Regina (org.). Memória e patrimônio: ensaios contemporâneos. Rio de Janeiro: Lamparina, 2009, p. 217-253.

HALBWACHS, Maurice. Memória Coletiva e Memória Histórica. In: HALBWACHS, Maurice. A Memória Coletiva. São Paulo:Vértice, 1990, p. 55-89.

LE GOFF, Jacques. História e Memória. $5^{a}$ edição. Campinas: Editora da Unicamp, 2003. 
NORA, Pierre, Entre Memória e História: a problemática dos lugares. In: Revista Projeto História. N 10. São Paulo: PUC-SP, 1993, p.7-28.

RICOEUR, Paul. A memória, a história, o esquecimento. Campinas: Editora da Unicamp, 2007.

WEINGARTEN, Sima. El Deber de Memoria. In: Revista Nuestra Memoria, ano $\mathrm{XI}, \mathrm{n}^{\circ}$ 26. Buenos Aires: Fundación Memoria del Holocausto, 2005. 